\title{
Síndrome aguda do tórax como primeira manifestação de anemia falciforme em adulto"
}

\author{
Hugo hyung Bok Yoo ${ }^{1}$, Nilva Regina Pelegrino², Ana Lúcia Oliveira de Carlos², \\ IRMA DE GODOY 3 , THAIS THOMAZ QUELUZ ${ }^{4}$
}

\begin{abstract}
A síndrome aguda do tórax (SAT) acomete portadores de anemia falciforme e é responsável por cerca de $25 \%$ dos óbitos. Relata-se o caso de um homem pardo de 45 anos, alcoolista crônico, sem nenhum antecedente de falcização, com quadro de pneumonia-símile havia sete dias. A radiografia simples do tórax mostrou infiltrado heterogêneo bilateral, com áreas de consolidação e broncograma aéreo e derrame pleural à esquerda. Outros exames laboratoriais revelaram anemia, leucocitose com desvio à esquerda e hipoxemia. Tratado com cefoxitina e amicacina, o paciente evoluiu rapidamente para insuficiência respiratória aguda e morreu 14 horas após a internação. Na necropsia, no exame

dos pulmões observaram-se intensa congestão, hemorragia intra-alveolar, dano alveolar difuso $e$ hemácias com morfologia falciforme. O caráter rápido, progressivo e freqüentemente mimetizado por outras doenças torna a SAT um evento dramático e de diagnóstico precoce difícil, sendo, entretanto, obrigatória tê-la sempre em mente, especialmente em um país com grande população da raça negra como o Brasil. (J Pneumol 2002;28(4):237-240)
\end{abstract}

\section{Acute chest syndrome as the first manifestation of sickle cell disease in a middle aged adult}

Acute chest syndrome is an affection, specially in young adults, of sickle cell disease and is responsible for $25 \%$ of the deaths. The authors report the case of an alcoholic 45-year-old mulatto man, without any previous manifestation of sickle cell disease, who presented with a pneumonia-like clinical picture with seven days of duration. The chest X-ray revealed bilateral lung infiltrates and spots of consolidation with air bronchograms, and left pleural effusion. The patient also had anemia and leukocytosis with neutrophilia. Treated with cefoxitin and amicacin, the patient developed acute respiratory insufficiency and died 14 hours after hospitalization. The necropsy showed lungs with intense congestion, intra-alveolar hemorrhage, diffuse alveolar damage, and sickle red blood cells. The progressive, fast, and severe character of the acute chest syndrome, which is frequently mimicked by other illnesses, makes the disease a dramatic and severe event of difficult earlier diagnosis. Therefore, in countries like Brazil, with a large black population, the physicians must always be aware of this possibility.

Descritores - Pneumonia. Anemia falciforme. Diagnóstico. Key words - Pneumonia. Sickle cell anemia. Diagnosis.

* Trabalho realizado na Disciplina de Pneumologia, Departamento de Clínica Médica, da Faculdade de Medicina de Botucatu, Unesp.

1. Doutor, Médico assistente.

2. Ex-Residente.

3. Livre-Docente; Professora Adjunta.

4. Livre-Docente; Professora Adjunta; Chefe da Disciplina.

Endereço para correspondência - Hugo Hyung Bok Yoo, Departamento de Clínica Médica, Faculdade de Medicina de Botucatu - Unesp - 18618-000 - Botucatu, SP. Tel. (14) 6822-2969; e-mail: hugo@fmb unesp.br

Recebido para publicação em $7 / 2 / 02$. Aprovado, após revisão, em 5/6/02.
Siglas e abreviaturas utilizadas neste trabalho

Glu - Glutamina

SAT - Síndrome aguda do tórax

SEG - Síndrome de embolia gordurosa

Val - Valina

\section{INTRODUÇ̃̃O}

A anemia falciforme, uma das doenças genéticas mais comuns entre indivíduos da raça negra, é causada pela substituição de aminoácido valina (Val) pela glutamina (Glu) na posição 6 da cadeia $\beta$-globina. Sua mortalidade apresenta distribuição bimodal, com um pico de incidência 


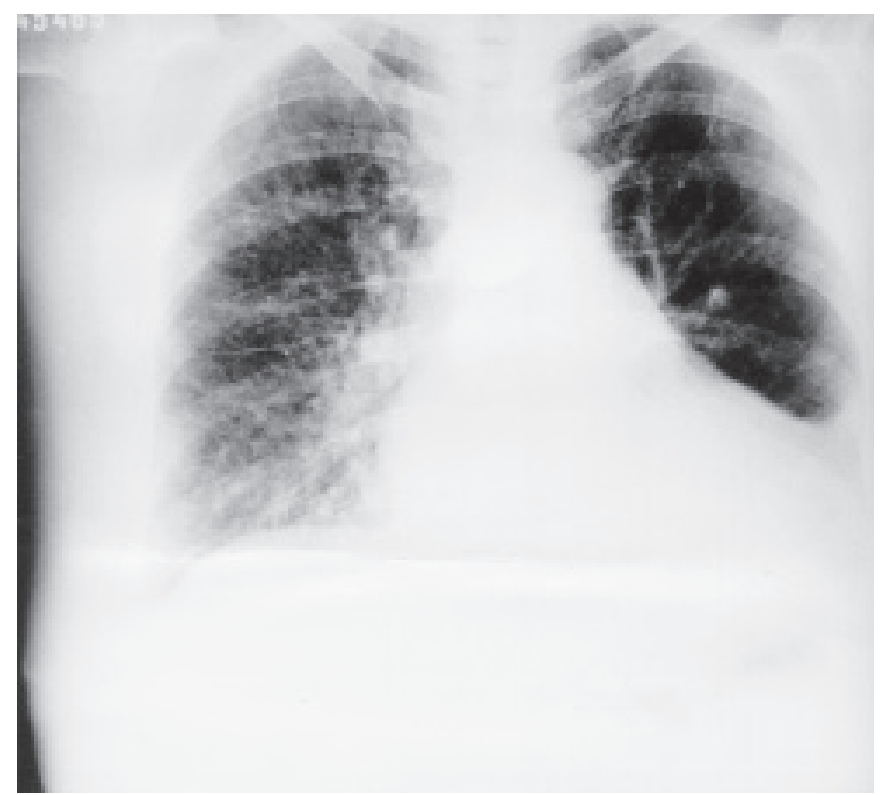

Figura 1 - Radiografia simples do tórax mostrando infiltrado heterogêneo bilateral, com áreas de consolidação e aerobroncograma e derrame pleural à esquerda. Há aumento da área cardíaca e sinais de hipertensão pulmonar.

elevada entre o nascimento até os cinco anos de idade, em geral decorrente de seqüestro esplênico ou infecção, e outro pico entre 20 e 25 anos de idade, geralmente causado pela síndrome aguda do tórax (SAT), caracterizada por febre, dor torácica, leucocitose e opacidade radiológica pulmonar ${ }^{(1,2)}$. Estima-se que cerca de $50 \%$ dos pacientes com anemia falciforme apresentem pelo menos um episódio de SAT no decurso da doença, sendo a segunda causa mais freqüente de hospitalizações destes pacientes e responsável por mais de $25 \%$ dos óbitos ${ }^{(3,4)}$.

Com o objetivo de chamar atenção para este quadro de pneumonia-símile que pode ter evolução fulminante e fatal, relatamos um caso raro de SAT em paciente de meiaidade sem antecedentes de falcização.

\section{RELATO DO CASO}

Homem de 45 anos, pardo, carpinteiro, tabagista e etilista crônico, referia dispnéia aos médios esforços, febre, tosse seca, adinamia e artralgia generalizada havia sete dias. Ao exame físico estava em regular estado geral, consciente, gemente, pálido, febril, desidratado, emagrecido, taquicárdico, taquidispnéico, com cianose de extremidades $(+/ 4+)$ e ausência de sinais inflamatórios articulares.

No tórax, apresentava submacicez nas bases, murmúrio vesicular diminuído globalmente, roncos e crepitações finas difusas. A radiografia simples do tórax revelou aumento da área cardíaca e infiltrado heterogêneo bilateral,

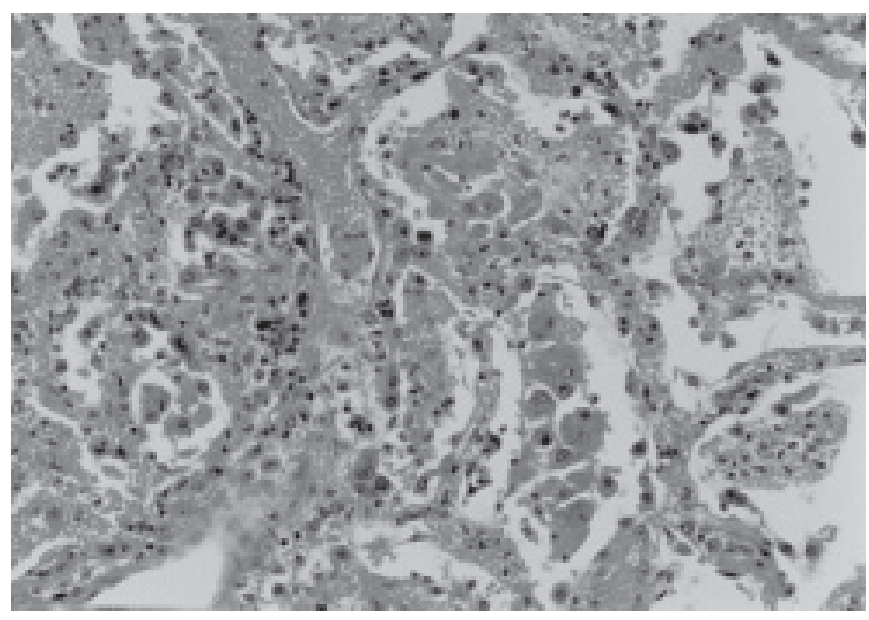

Figura 2 - Microscopia óptica do pulmão mostrando intensa congestão vascular, hemorragia intra-alveolar e dano alveolar difuso (HE X600).

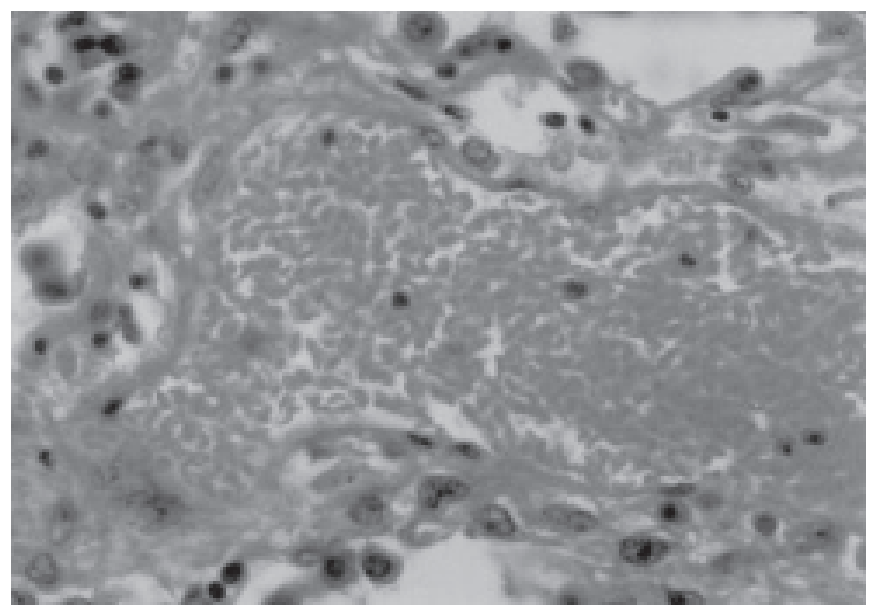

Figura 3 - Microscopia óptica do pulmão evidenciando vaso obliterado por hemácias com morfologia falciforme (HE X800).

com áreas de consolidação e broncograma aéreo e derrame pleural à esquerda (Figura 1). Outros exames laboratoriais revelaram anemia, leucocitose com desvio à esquerda e hipoxemia.

Foram feitas as hipóteses diagnósticas de pneumonia adquirida na comunidade, pneumonia atípica, tuberculose ou infecção oportunista por imunodeficiência; iniciouse o tratamento com medidas gerais e antibioticoterapia com cefoxitina e amicacina enquanto se aguardavam os resultados dos exames específicos. O paciente evoluiu com deterioração rápida do quadro clínico, necessitando de ventilação mecânica e, 14 horas após a internação, teve parada cardiorrespiratória não reversível.

A necropsia revelou pulmões com intensa congestão e hemorragia intra-alveolar, dano alveolar difuso e hemácias com morfologia falciforme (Figuras 2 e 3). A cultura 
de fragmentos do pulmão foi negativa para bactérias, fungos e BAAR. No coração foram evidenciadas extensa necrose de músculo papilar e trombose de vários ramos da artéria coronária com múltiplas áreas de infarto do miocárdio.

\section{DisCUSSÃO}

Embora 15 a $43 \%$ dos casos com anemia falciforme apresentem SAT no decorrer da doença ${ }^{(1-4)}$, a raridade do presente relato está no fato de um paciente na $5^{\mathrm{a}}$ década de vida, sem nenhum antecedente de falcização, ter apresentado como primeira manifestação da doença um episódio de SAT com evolução fulminante. O alcoolismo crônico, o quadro clínico e os achados radiológicos e laboratoriais sugeriram a hipótese diagnóstica inicial de pneumonia, que não respondeu à antibioticoterapia empírica convencional.

A SAT é freqüentemente desencadeada após uma crise venoclusiva $^{(2,5)}$ e diversos fatores podem contribuir para a insuficiência respiratória aguda associada à SAT, tais como infecção, embolia gordurosa, hiper-hidratação, hipoxemia, microatelectasias ${ }^{(3)}$. Sua gravidade varia de acordo com a idade do paciente, sendo que em crianças a manifestação clínica é mais branda e, provavelmente, o desencadeante é uma infecção. No entanto, em adultos jovens há predomínio de eventos trombóticos pulmonares que resultam em hipoxemia, hospitalização prolongada e alta taxa de mortalidade ${ }^{(4)}$

Pacientes com anemia falciforme têm maior risco de infecções devido ao defeito de opsonização e fagocitose decorrentes da alteração de ativação do sistema complemento, hipoesplenia funcional e redução dos anticorpos circulantes específicos aos pneumococos e antígenos polissacárides ${ }^{(5)}$. Acredita-se que, em conseqüencia desses defeitos imunológicos, muitos dos episódios de SAT possam ter origem pneumocócica, porém o real papel das bactérias como causadoras de SAT não está ainda bem esclarecido. Outros agentes como Mycoplasma pneumoniae, Chlamydia pneumoniae e vírus são também considerados como possíveis causadores infecciosos de SAT, principalmente em população pediátrica ${ }^{(1,5,6)}$. A presença de infecção pulmonar no presente caso pode ser excluída pela negatividade das culturas realizadas em diversos fragmentos de tecido pulmonar.

A doença pulmonar vasoclusiva é secundária à deformidade estrutural das hemácias que, associada à hiperplasia intimal e ao aumento da liberação dos fatores de adesão endotelial, contribui para formação de trombos microvasculares, com conseqüente infarto pulmonar ${ }^{(1)}$. Os achados do exame anatomopatológico dos pulmões do paciente foram similares aos descritos na literatura sobre SAT: congestão, edema, necrose focal de parede alveolar com inflamação aguda, membrana hialina, trombos fibrinosos nas artérias de pequeno calibre, focos de infarto pulmonar e áreas de ruptura dos septos alveolares com hemorragia intra-alveolar contendo hemácias falciformes $^{(7)}$

Em cerca de um terço dos pacientes com SAT a radiografia simples de tórax pode estar normal inicialmente e, dependendo da evolução, que pode variar de horas a dias, as anormalidades radiográficas podem acentuar-se com infiltrado localizado, lobar ou difuso, uni ou bilateral, e/ ou derrame pleural ${ }^{(1,8,9)}$. Como infarto pulmonar e pneumonia nem sempre são diferenciáveis à radiografia simples de tórax e à cintilografia de ventilação-perfusão $e$ como a arteriografia pulmonar com contrastes hipertônicos é contra-indicada em pacientes com anemia falciforme pelo alto risco de induzir alteração estrutural na hemoglobina, a tomografia computadorizada de alta resolução tem sido sugerida como bom método para detecção de microêmbolos ${ }^{(9)}$.

Os principais diagnósticos diferenciais da SAT são pneumonia e doença pulmonar vasoclusiva. Outras condições que podem simular SAT são síndrome de embolia gordurosa (SEG) e infarto ósseo. A SEG geralmente está associada à dor óssea, alteração do nível de consciência, trombocitopenia, hipocalcemia e hiperuricemia; petéquias na conjuntiva e no tórax podem reforçar o diagnóstico ${ }^{(3-6,10)}$. Acredita-se que a dor local provocada pelo infarto ósseo, principalmente das costelas, do esterno e das vértebras, possa resultar em hipoventilação, atelectasia, hipercapnia e hipoxemia ${ }^{(10,11)}$.

Para prevenção da SAT, pacientes com anemia falciforme devem receber vacinação antipneumocócica e antiinfluenza ${ }^{(1,6)}$. Também, a antibioticoterapia empírica é recomendada nos pacientes com suspeita de pneumonia adquirida na comunidade, visando cobrir os agentes mais comuns, que podem variar de acordo com a história, quadro clínico, idade e presença ou não de outras doenças de base. Hidratação com solução salina hipotônica deve ser utilizada para prevenir ou reverter a depleção de volume intravascular e diminuir a osmolaridade em crise de falcização(1,3,6).

Em situações restritas como em pacientes com anemia e hipoxemia graves, a transfusão de sangue visando reduzir a concentração de hemoglobina S para 20 a $30 \%$ e manter hematócrito em torno de $30 \%$ pode ser útil, porém a transfusão crônica é controversa. Deve ser lembrado que as transfusões desnecessárias podem aumentar a viscosidade sanguínea e que níveis de hemoglobina em torno de $8 \mathrm{~g} / \mathrm{dl}$ são normais para indivíduos portadores de anemia falciforme ${ }^{(6)}$. Nos Estados Unidos da América, o uso de hidroxiuréia foi aprovado para tratamento da anemia falciforme, por ser uma droga que aumenta os níveis de hemoglobina fetal, alterando, conseqüentemen- 
te, a cinética e o equilíbrio dinâmico da polimerização da hemoglobina $\mathrm{S}$, reduzindo as taxas de crises venoclusivas e de SAT ${ }^{(3)}$. Entretanto, essa droga não foi ainda estudada em pacientes adultos com anemia falciforme e hipertensão pulmonar.

Finalmente, o caráter rápido, progressivo e freqüentemente mimetizado por outras doenças torna a SAT um evento dramático e de diagnóstico precoce difícil. Portanto, é obrigatória, na medida do possível, sua prevenção e tê-la sempre em mente, especialmente em um país com grande população da raça negra como o Brasil.

\section{REFERÊNCIAS}

1. Haynes J, Kirkpatrick MB. The acute chest syndrome of sickle cell disease. Am J Med Sci 1993;305:326-30.

2. Platt OS, Brambilla DJ, Rosse WF, Milner PF, Castro O, Steinberg $\mathrm{MH}$, Klug PP. Mortality in sickle cell disease: life expectancy and risk factors for early death. N Engl J Med 1994;330:1639-46.

3. Minter KR, Gladwin MT. Pulmonary complications of sickle cell anemia. A need for increased recognition, treatment, and research. Am J Respir Crit Care Med 2001;164:2016-9.

4. Vichinsky EP, Styles LA, Colangelo LH, Wright EC, Castro O, Nickerson $\mathrm{B}$. Acute chest syndrome in adults with sickle cell disease: clinical presentation and course. Cooperative Study of Sickle Cell Disease. Blood 1997;89:1787-92.

5. Vichinsky EP, Neumayr LD, Earles NA, Williams R, Lennette ET, Dean $\mathrm{D}$, et al. Causes and outcomes of the acute chest syndrome in sickle cell disease: National Acute Chest Syndrome Group. N Engl J Med 2000;342:1855-65.

6. Gladwin MT, Rodgers GP. Pathogenesis and treatment of acute chest syndrome of sickle-cell anaemia. Lancet 2000;355:1476-8.

7. Hasleton PS, Orr K, Webster A, Lawson RAM. Evolution of acute chest syndrome in sickle cell trait: an ultrastructural and light microscopic study. Thorax 1989;44:1057-8.

8. Martin L, Buonomo C. Acute chest syndrome of sickle cell disease: radiographic and clinical analysis of 70 cases. Pediatr Radiol 1997; 27:637-41.

9. Bhalla M, Abboud MR, McLoud TC, Shepard JAO, Munden MM, Jackson SM, et al. Acute chest syndrome in sickle cell disease: CT evidence of microvascular occlusion. Radiology 1993;187: 45-9.

10. Maitre B, Habibi A, Roudot-Thoraval F, Bachir D, Belghiti DD, Galacteros $\mathrm{F}$, et al. Acute chest syndrome in adults with sickle cell disease. Therapeutic approach, outcome, and results of BAL in a monocentric series of 107 episodes. Chest 2000;117:1386-92.

11. Gelfand MJ, Daya SA, Rucknagel DL, Kalinyak KA, Paltiel HJ. Simultaneous occurrence of rib infarction and pulmonary infiltrates in sickle cell disease patients with acute chest syndrome. J Nucl Med 1993;34: 614-8. 